\title{
Experimental Research on Enhanced Denitrification by Biological Agents
}

\author{
Xiaoyu Liu ${ }^{1,2^{*}}$, Ruozheng $\mathrm{Li}^{1,2}$, Zhengkun $\mathrm{Li}^{1,2}$, Can Wang ${ }^{1,2}$ \\ ${ }^{1}$ Nari Group Corporation/State Grid Electric Power Research Institute, Nanjing 210000, Jiangsu Province, China \\ ${ }^{2}$ Beijing Guodian Futong Science and Technology Development Co., Ltd., Beijing 100070, China
}

\begin{abstract}
Biological agents play a significant role in sewage treatment, with good removal effect, low sludge yield, good performance, and shorten the system start-up time, impact load resistance and stability enhancement. This paper describes the characteristics of biological agents and the effect of biological agents on wastewater denitrification was investigated through experiments, so as to provide effective basis support for the wide application of biological agents in the field of urban sewage treatment. The experiment showed that through reasonable addition of biological agents, the removal rates of $\mathrm{COD}, \mathrm{NH}_{3}-\mathrm{N}$ and $\mathrm{TN}$ in low pollutant sewage treatment were increased by $41 \%, 15 \%$ and $62 \%$ respectively.
\end{abstract}

\section{Biological agents and biofortification techniques}

In recent years, with the increase of environmental protection requirements and the continuous development of environmental biotechnology, bioremediation, as a water pollution treatment technology with low investment, high efficiency, convenient operation and flexibility, has been gradually developed and applied in projects, and is gradually being widely valued and applied worldwide. Bioaugmentation presents a quick and cost effective way to solve wastewater treatment problems that would traditionally be solved with expensive capital enhancements[1-2].

This study adopts BiOWiSH ${ }^{\mathrm{TM}}$ technology which creates a composite biocatalyst from a unique blend of microorganisms, enzymes, and co-factors. This composite biocatalyst enhances biochemical reactions in wastewater treatment plants, enabling the process to work faster and more efficiently than native biological organisms alone. $\mathrm{BiOWiSH}^{\mathrm{TM}}$ biocatalysts coexist with existing wastewater biology to enhance their rate of reaction, resulting in a more efficient biological treatment process[3].

\section{Advantages of biological agents in the application of municipal sewage}

Biological agents are bacterial liquid agents selected from the nature with specific degradation functions. The application of biological agents can effectively shorten the time of microbial culture and domestication, improve the concentration of microorganisms in the biological treatment system, and thus improve the work efficiency. In addition, biofortified agents are easy to operate, safe to use and can save energy. For example, in the sewage treatment of urban sewage, bacteria can be activated and added to the sewage, which can erode the organic particles of grease in the sewage, and has an obvious effect on the treatment of grease blockage in the sewage. In addition, the carbohydrates, nitrogen and phosphorus and other nutrients in urban sewage provide sufficient nutrients for the growth and reproduction of microorganisms. The use of special microbial agents to enhance the treatment of urban sewage can significantly improve the removal efficiency of organic matter in sewage, reduce the generation of solid substances, enhance nitrification, enhance the effect of denitrification and phosphorus removal, and thereby improve the water purification efficiency of urban sewage[4-6].

\section{The experiment part}

\subsection{The experiment purpose}

This experiment is expected to study the application effect of biological reagent in the process of urban sewage treatment by using BiOWiSH ${ }^{\mathrm{TM}}$ technology company's biological agents. Under aerobic conditions, the effects of adding biological reagents on organic pollutant in the treated water and the changes of TN indicators were investigated to study BiOWiSH ${ }^{\mathrm{TM}}$ preparation's bioremediation effect on urban sewage.

\subsection{The water sample}

The drainage of the company apartment was choosed as the water sample of this study。 The water quality is shown in the table 1 .

\footnotetext{
*Corresponding author's e-mail: liuxiaoyu1@sgepri.sgcc.com.cn
} 
Table 1. The water quality situation.

\begin{tabular}{|c|c|c|c|c|}
\hline $\begin{array}{c}\mathrm{COD} \\
(\mathrm{mg} / \mathrm{L})\end{array}$ & $\begin{array}{c}\mathrm{NH}_{3}-\mathrm{N} \\
(\mathrm{mg} / \mathrm{L})\end{array}$ & $\mathrm{pH}$ & $\begin{array}{c}\mathrm{NO}_{3}-\mathrm{N} \\
(\mathrm{mg} / \mathrm{L})\end{array}$ & $\mathrm{TN}(\mathrm{mg} / \mathrm{L})$ \\
\hline 79 & 29.6 & 7.28 & 1.03 & 31.1 \\
\hline
\end{tabular}

\subsection{Experimental materials and methods}

\subsubsection{Experimental materials}

The experiment was carried out with the biological agents which belongs to $\mathrm{BiOWiSH}^{\mathrm{TM}}$ in the United States and the AMBR device for the study of denitrification. By investigating the removal rates of $\mathrm{COD}, \mathrm{NH}_{3}-\mathrm{N}$ and $\mathrm{TN}$, this paper studies whether biological agents have positive effects on sewage treatment, especially on denitrification.

(1) Chemicals and agents

BiOWiSH ${ }^{\mathrm{TM}}$ biological agents, glucose, $\mathrm{KMnO}_{4}$, $\mathrm{C}_{2} \mathrm{Na}_{2} \mathrm{O}_{4}, \quad \mathrm{~K}_{2} \mathrm{~S}_{2} \mathrm{O}_{8}, \quad \mathrm{C}_{7} \mathrm{H}_{6} \mathrm{O}_{3}, \quad \mathrm{C}_{4} \mathrm{O}_{6} \mathrm{H}_{4} \mathrm{KNa}$, $\mathrm{Na}_{2} \mathrm{Fe}(\mathrm{CN})_{5} \mathrm{NO}_{2} \mathrm{H}_{2} \mathrm{O}, \mathrm{NaClO}, \mathrm{NaOH}, \mathrm{HCl}, \mathrm{H}_{2} \mathrm{SO}_{4}$.

(2) Devices

AO plus MBR, pumps, air compressor, oxygen analyzer.

(3) Detection methods
GB/T 15456-2008 Industrial circulating cooling water - Determination of the chemical oxygen demand Potassium permanganate method.

HJ 536-2009 Water quality-Determination of ammonia nitrogen-Salicylic acid spectrophotometry.

HJ 636-2012 Water quility-Determination of total nitrogen UV spectrophotometric method-Alkaline potassium persulfate digestion method.

\subsubsection{Experimental methods}

The device parameters were set according to these parameters:

(1) flow rate: $6 \mathrm{~L} / \mathrm{h}$;

(2) HRT: $A=7.31 \mathrm{~h}, \mathrm{O}=18 \mathrm{~h}$;

(3) mixture reflux ratio: $200 \%-400 \%$;

(4) dosage of biological preparation: $5 \mathrm{ppm}$;

(5) dosage of glucose demand: $\mathrm{C} / \mathrm{N}=4$.

After adding activated sludge, sewage and nutrients, aerats for one day, the experiment was carried out according to the experimental methods in table 2 .

Table 2. Experimental methods.

\begin{tabular}{ccc}
\hline The serial number & Conditions & Reflux ratio \\
\hline 1 & nothing added & $200 \%$ \\
2 & only biological agents & $200 \%$ \\
3 & only biological agents & $400 \%$ \\
4 & only glucose & $400 \%$ \\
5 & biological agents and glucose & $400 \%$ \\
\hline
\end{tabular}

\subsection{Conclusion and discussion}

(1) Conduct experiments according to serial numbers land 2 in table 2 . The indexes changes of COD, $\mathrm{NH}_{3}-\mathrm{N}$ and $\mathrm{TN}$ are shown in figure 1-3.

In experiment 1 , the removal rates of $\mathrm{COD}, \mathrm{NH}_{3}-\mathrm{N}$ and $\mathrm{TN}$ were $35 \%, 82 \%$ and $22 \%$ respectively. In experiment 2, the removal rates of $\mathrm{COD}, \mathrm{NH}_{3}-\mathrm{N}$ and $\mathrm{TN}$ were $76 \%, 97 \%$ and $23 \%$ respectively.

Through comparison of experiments 1 and 2, it was found that the removal rate of $\mathrm{COD}$ and $\mathrm{NH}_{3}-\mathrm{N}$ respectively increased by $41 \%$ and $15 \%$ by adding biological agents, it can be seen from the COD change curve in figure 1 that it takes about 8 days for COD to be reduced to $50 \mathrm{mg} / \mathrm{L}$ in experiment 1 , and only 4 days for COD to be reduced to $20 \mathrm{mg} / \mathrm{L}$ after adding biological agents. This shows that biological agents can not only improve the removal rate of COD, but also improve the removal speed, which is also applied to the $\mathrm{NH}_{3}-\mathrm{N}$ change curve in figure 2.

The removal rate of $\mathrm{TN}$ in both experiments was very low, and the removal rate did not increase after adding biological agents.

It can be concluded that the reflux ratio of $200 \%$ and only adding biological agents can significantly improve the removal rate of $\mathrm{COD}$ and $\mathrm{NH}_{3}-\mathrm{N}$, but it has no effect on the removal rate of TN. 


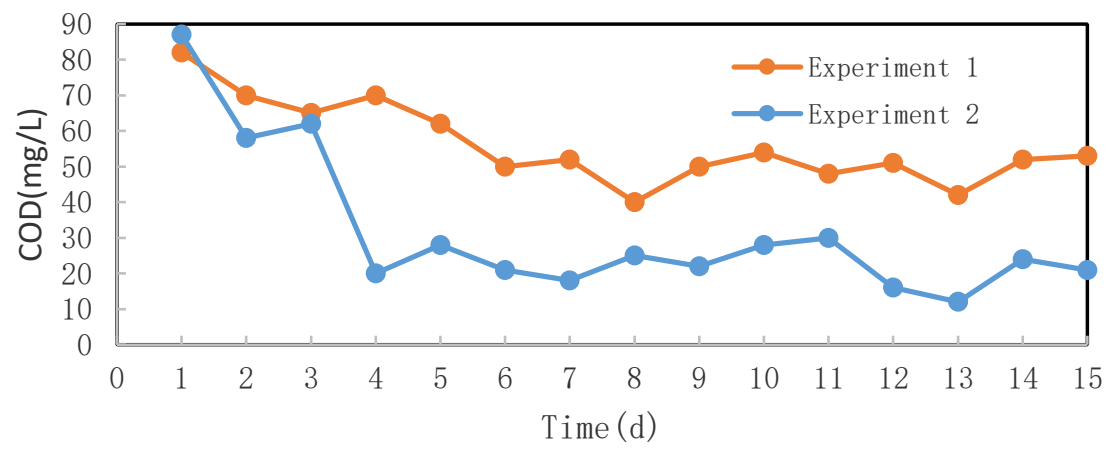

Figure 1. The trend of COD in two experiments.

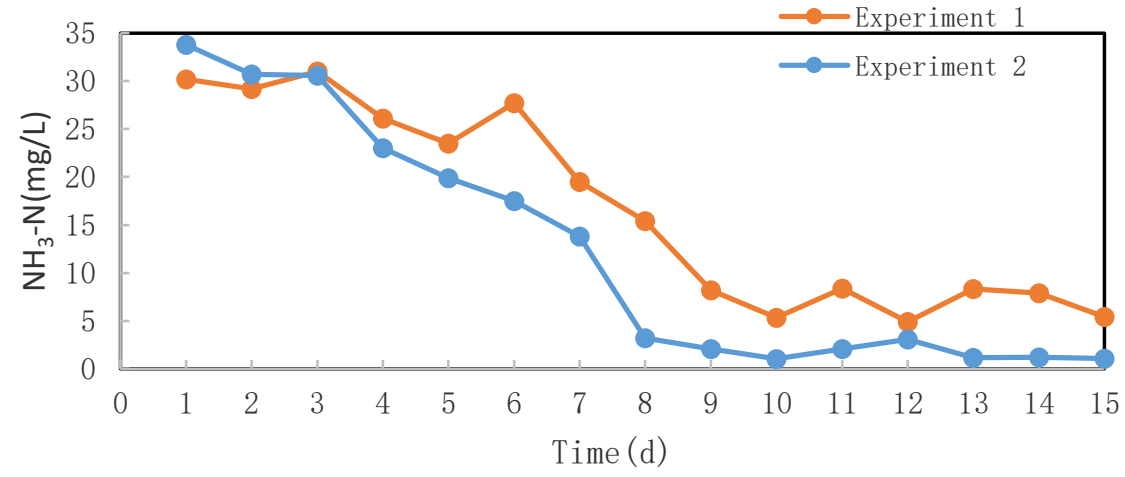

Figure 2. The trend of $\mathrm{NH}_{3}-\mathrm{N}$ in two experiments.

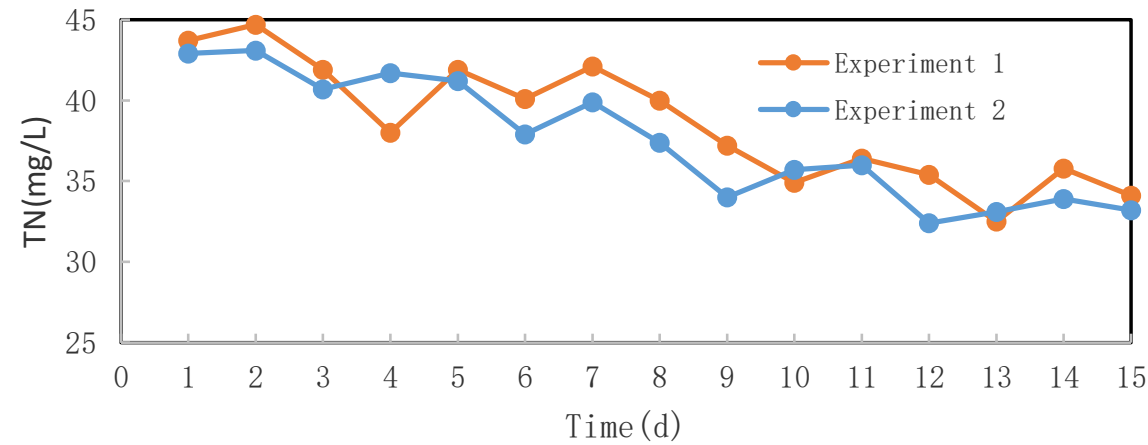

Figure 3. The trend of TN in two experiments.

(2) Continue the experiment according to the numbers 3-5 in table 2 . Only the index change of $\mathrm{TN}$ was investigated, as shown in figure 4. 


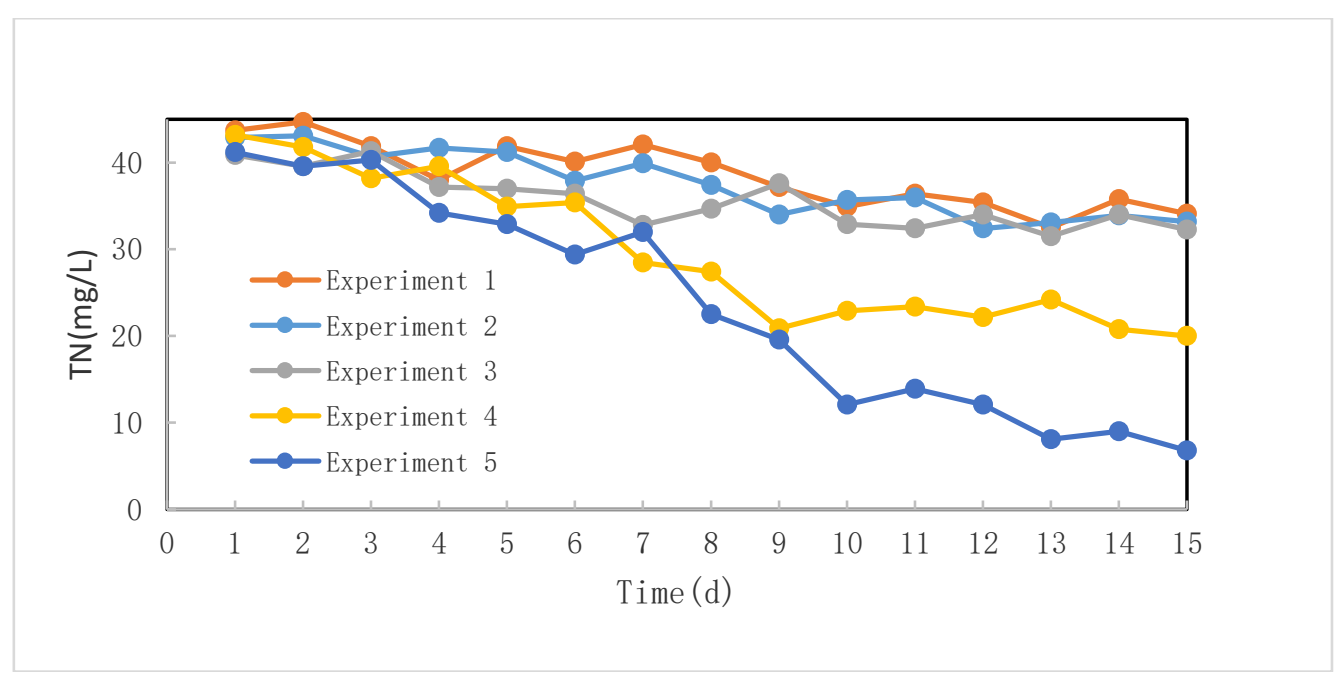

Figure 4. The trend of TN in five experiments.

It can be clearly seen from table 3 that on the condition of adding biological agents only, the reflux ratio increased from $200 \%$ to $400 \%$, the denitrification rate decreased, which is contrary to the the oretical value. Considering the reasons, probably because a large amount of dissolved oxygen in the aerobic zone enters the anoxic zone and damages the denitrification environment. And by increasing the reflux ratio, the denitrification bacteria could not utilize enough organic matter during denitrification, which affected the denitrification reaction and reduced the denitrification rate.

It can be seen from experiment 3-5, under the condition of reflux ratio of $400 \%$, adding glucose can effectively improve the denitrification rate, and adding glucose and biological agents together can improve the denitrification rate to $84 \%$.

Therefore, it can be concluded that the addition of nutrients should be taken into account in the enhanced denitrification by biological agents, so that the denitrification rate can be effectively improved.

Table 3. Denitrification rateunder different conditions.

\begin{tabular}{cccc}
\hline The serial number & Conditions & Reflux ratio & Denitrification rate \\
\cline { 1 - 3 } 1 & nothing added & $200 \%$ & $22 \%$ \\
2 & only biological agents & $200 \%$ & $23 \%$ \\
3 & only biological agents & $400 \%$ & $21 \%$ \\
4 & only glucose & $400 \%$ & $54 \%$ \\
5 & biological agents and glucose & $400 \%$ & $84 \%$ \\
\hline
\end{tabular}

\section{The experimental conclusion}

(1) Only adding biological agents can remove COD and $\mathrm{NH}_{3}-\mathrm{N}$ effectively, but not TN.

(2) Adding carbon source can increase the denitrification rate to $54 \%$, and adding carbon source and biological agent together can increase the denitrification rate to $84 \%$.

\section{References}

1. Liu, Z., Huang, R.M., He, J.C.. (2014) Bio-augmentation of SBR with Microbial Agent. Chinese Journal of Environmental Engineering, 8: 1988-1991.

2. Li, Y., Chen,J. etc. (2014) Study on Application of Decontamination Biologics in Water Quality Improvement of Urban Watercourses. TheWater Environment, 4: 30-32.
3. BiOWiSH ${ }^{\text {тм }}$ Industrial Wastewater Brochure Ir.

4. Chen, L.C.. (2017) Research and application of microorganism preparation in water treatment. Applied Chemical Industry, 46: 986-987.

5. Yuan, D.Y.. (2015) Effect evaluation and influence factor analysis of biofortification technology in wastewater pretreatment. Resource Conservation and Environmental Protection, 3: 175-176.

6. Wang,P.. (2017) Study on The Mechanism and Application of Biofortification Technology in Wastewater Treatment. Resource Conservation and Environmental Protection, 3: 175-176. 